\title{
Response to Sherry Leonard and Laura Giordano's Letter
}

We thank Drs. Leonard and Giordano for their thoughtful comments and interpretations pertaining to our study of smoking and visuospatial working memory (VSWM) function in schizophrenic and non-schizophrenic control subjects (George et al., 2002a). As they clearly point out, converging lines of evidence from independent laboratories have suggested differential effects of smoking in a variety of neurocognitive paradigms in schizophrenic patients as compared with controls. Furthermore, there is evidence that there may be differences between non-smoking and smoking schizophrenic patients insofar as illness severity (Hall et al., 1995), cognitive function (George et al., 2002a) and treatment response to antipsychotic agents (McEvoy et al., 1999). Whether these differences are solely attributable to nicotine/smoking effects or to independent factors (e.g. different biological subtypes of schizophrenia that predict a vulnerability to becoming a smoker or not) remains to be determined.

The model proposed by Leonard and Giordano makes biological and clinical sense, and can inform further hypothesis-driven research directed toward understanding the long-standing observation of higher rates of cigarette smoking in patients with schizophrenia and other mental disorders. In the rat, activation of pre-synaptic high- and low-affinity nicotinic receptors stimulates midbrain dopamine (DA) neurons projecting to the prefrontal cortex (PFC) (George et al., 2000a). Whether differences in receptor number, and / or differences in receptor dynamics, between schizophrenic and

Address correspondence to: Tony P. George, M.D., Rm. S-109, Substance Abuse Center, Connecticut Mental Health Center, 34 Park Street, New Haven, CT 06519, USA. Tel: +1-203-974-7362; Fax: +1-203-974-7366.

E-mail address: tony.george@yale.edu

Supported in part by U.S. Public Health Service grants R01-DA14039, R01-DA-13672 and K12-DA-00167. control smokers influence PFC DA systems (and postsynaptic $D_{1}$ receptor-mediated signaling), which are implicated in spatial working memory impairments (Williams and Goldman-Rakic, 1995) and in the pathophysiology of schizophrenia, also needs to be evaluated. In further support of their proposed model, recent preliminary data from our laboratory suggests that after overnight smoking abstinence, smoking re-challenge leads to partial reversal of smoking abstinence-induced deficits in VSWM in schizophrenics, and worsening of VSWM in controls; the effects of smoking re-challenge in both groups are blocked by pre-treatment with the nicotinic receptor antagonist mecamylamine (George et al., 2001), suggesting that stimulation of nicotinic receptors mediates these differential effects of smoking rechallenge in schizophrenic patients as compared with controls.

One critical methodological approach will be the use of $2 \times 2$ designs controlling for the presence or absence of mental illness (e.g. schizophrenic or control) and smoking status (e.g. being a smoker or non-smoker) (George et al., 2001; George et al., 2002a). A second methodological issue relates to the effects of nicotine (or a nicotinic agonist which does not lead to immediate nicotinic receptor desensitization) on neurocognitive outcomes in schizophrenic patients who are non-smokers, so that the direct effects of nicotine, independent of smoking and smoking abstinence, on these outcomes can be determined.

Ultimately, the integration of biochemical, pharmacological, human molecular genetic, neurocognitive, receptor neuroimaging and clinical approaches to these questions (Adler et al., 1998; Breese et al., 2000) shows considerable promise for parsing the biological relationships between nicotine addiction and mental disorders. Such an understanding may lead to improved treatments for schizophrenia and other mental disorders associated with high rates of smoking. Further- 
more, given that smoking-related medical illness and mortality are higher in schizophrenics than in the general population of smokers (Lichtermann et al., 2001), these studies may inform the development of new and effective treatments for smoking cessation (George et al., 2000b; Evins et al., 2001; George et al., 2002b) in these patients.

Tony P. George, M.D.

Jennifer C. Vessicchio, M.S.W.

Angelo Termine, B.S.

Aisha Seyal, B.S.

Brigid S. Boland

Margaret A. Fonder

Thomas R. Kosten, M.D.

Bruce E. Wexler, M.D.

Program for Research in Smokers with

Mental Illness (PRISM)

Division of Substance Abuse

Department of Psychiatry,

Yale University School of Medicine

\section{REFERENCES}

Adler LE, Hoffer LD, Waldo M, et al. (1998): Schizophrenia, sensory gating and nicotinic receptors. Schizophr Bull 24:189-202

Breese CR, Lee MJ, Adams CE, Sullivan B, Logel J, Gillen KM, Marks MJ, Collins AC, Leonard S (2000): Abnormal regulation of high affinity nicotinic receptors in subjects with schizophrenia. Neuropsychopharmacology 23:351-364

Evins AE, Mays VK, Rigotti NA, Tisdale T, Cather C, Goff DC (2001): A pilot trial of bupropion added to cognitive behavioral therapy for smoking cessation in schizophrenia. Nicotine \& Tobacco Research 3:397-403
George TP, Verrico CD, Picciotto MR, Roth RH (2000a): Nicotinic modulation of mesoprefrontal dopamine systems: Pharmacologic and neuroanatomic characterization. J Pharmacol Exp Ther 295(1):58-66

George TP, Zeidonis DM, Feingold A, Pepper WT, Satterburg CA, Winkel J, Rounsaville BJ, Kosten TR (2000b): Nicotine transdermal patch and atypical antipsychotic medications for smoking cessation in schizophrenia. Am J Psychiatry 157(11): 1835-1842

George TP, Vessicchio JC, Termine A, Bregartner T, Boland B, Fonder M, Kim A, Wexler BE (2001). A laboratory study of nicotinic receptor mechanisms and cognitive function in schizophrenia. American College of Neuropsychopharmacology, 40th Annual Meeting, Waikoloa, Hawaii

George TP, Vessicchio JC, Termine A, Sahady DM, Head CA, Pepper WT, Kosten TR, Wexler BE (2002a): Effects of smoking abstinence on visuospatial working memory function in schizophrenia. Neuropsychopharmacology 26:75-85

George TP, Vessicchio JC, Termine A, Bregartner TA, Feingold A, Rounsaville BJ, Kosten TR (2002b): A placebocontrolled study of bupropion for smoking cessation in schizophrenia. Biol Psychiatry 52:53-61

Hall RG, Duhamel M, McClanahan R, Miles G, Nason C, Rosen S, Schiller P, Tao-Yonenaga L, Hall SM (1995): Level of functioning, severity of illness, and smoking status among chronic psychiatric patients. J Nerv Ment Dis 183:468-471

Lichtermann D, Ekelund E, Pukkala E, Tanskanen A, Lonnqvist J (2001): Incidence of cancer among persons with schizophrenia and their relatives. Arch Gen Psychiatry 58:573-578

McEvoy JP, Freudenreich O, Wilson WH (1999): Smoking and therapeutic response to clozapine in patients with schizophrenia. Biol Psychiatry 46:125-129

Williams GV, Goldman-Rakic PS (1995): Modulation of memory fields by dopamine D1 receptors in the prefrontal cortex. Nature 376:572-575 